\title{
Técnicas de transferencia nerviosa en lesiones del miembro superior
}

\section{Nerve Transfer Techniques in Injuries of the Upper Limb}

\author{
Francisco Martínez Martínez ${ }^{1}$ \\ B. Ñ́guez Sevilla ${ }^{2}$
${ }^{1}$ FEA de Cirugía Ortopédica y Traumatología del Hospital Clínico Universitario Virgen de la Arrixaca. Murcia, Spain
2 Médico Interno Residente de Cirugía Ortopédica y Traumatología del Hospital Clínico Universitario Virgen de la Arrixaca, Murcia, Spain
${ }^{3}$ FEA de Cirugía Ortopédica y Traumatología del Hospital General de Alicante, Alicante, Spain

J. García García ${ }^{2}$

A. García López 3
Address for correspondence Francisco Martínez Martínez, C/ Canovas del Castillo $n^{\circ} 7-4^{\circ}$ a. 30003-Murcia, Spain
(e-mail: fmtnez@gmail.com).

Rev Iberam Cir Mano 2017;45:57-67.

\section{Resumen}

Palabras Clave

- Transferencias nerviosas

- plexo braquial

- lesión nerviosa

\section{Abstract \\ Keywords \\ - nerve transfers \\ - brachial plexus \\ - nerve injury}

Las lesiones nerviosas proximales tanto de miembro superior como del plexo están asociadas con un mal pronóstico, incluso con una reparación temprana. En las últimas décadas ha existido un aumento de técnicas de transferencia nerviosa, mediante las cuales un nervio periférico denervado es reinervado por un nervio donante sano. Las transferencias nerviosas están indicadas en lesiones del plexo braquial proximal donde no es posible el injerto o en lesiones proximales de los nervios periféricos con largas distancias de reinervación.

Las transferencias de nervios representan una revolución en la cirugía del nervio periférico y ofrecen el potencial para la recuperación funcional superior en lesiones nerviosas graves. En las lesiones completas del plexo braquial se investiga la existencia de raíces disponibles para utilizarlas como donantes de axones (transferencias intraplexuales). En caso de no existir, se recurre a las transferencias de nervios que no forman parte del plexo (transferencias extraplexuales) como pueden ser el nervio espinal accesorio, el nervio frénico, los nervios intercostales, etc.

En el presente artículo de actualización, se hará una revisión de las técnicas quirúrgicas de transferencias nerviosas motoras tanto intra como extraplexuales.

Proximal nerve injuries of the upper limb or the braquial plexus are associated with a poor prognosis, even with prompt repair. In the last few decades, an increase in nerve transfer techniques has occurred, by which a denervated peripheral nerve is reinnervated by a healthy donor nerve. Nerve transfers are indicated in proximal brachial plexus injuries in which grafting is not possible, or in proximal injuries of peripheral nerves with long reinnervation distances.

Nerve transfers represent a revolution in peripheral nerve surgery, and offer the potential for superior functional recovery in severe nerve injuries. In complete brachial plexus injuries, the existence of nerve roots (intraplexual transfers) is being studied. If they do not exist, the transference of nerves out of the plexus is performed received

March 2, 2017

accepted

April 1, 2017
DOI https://doi.org/

10.1055/s-0037-1602765. ISSN $1698-8396$.
Copyright $\odot 2017$ by Thieme Revinter

Publicações Ltda, Rio de Janeiro, Brazil
License terms

(ㄷ) (i) $\ominus$ (5) 
(extraplexual transfers), such as the spinal accessory nerve, the phrenic nerve, the intercostal nerves, etc.

In this update paper, the different motor intra- and extraplexual nerve transfer techniques are reviewed.

\section{Introducción}

En los años 70 y 80 hubo un gran entusiasmo por la cirugía reconstructiva del plexo braquial gracias a la aparición de técnicas innovadoras, aunque ese entusiasmo decayó debido al estancamiento de los resultados obtenidos.

Definimos transferencia nerviosa o "Neurotización" como aquella técnica quirúrgica consistente en la sección de un nervio o fascículo del mismo, que llamaremos donante, sacrificando su función original, para unirlo con el cabo distal de un nervio o fascículo receptor, cuya función se ha perdido debido a una lesión y se busca restablecer. Con esa técnica es inevitable la pérdida de función del nervio donante, por lo que es necesario valorar el riesgo-beneficio de la misma.

Inicialmente ese tipo de técnica estaba indicada cuando no se podía hacer una neurorrafia, con o sin injerto, del nervio lesionado. Ese tipo de situación se produce en el plexo braquial cuando una raíz cervical se avulsiona de su origen a nivel de la médula; sin embargo, y dados los buenos resultados obtenidos con esa técnica, las transferencias nerviosas se han estado empleando en algunos casos en los que las raíces del plexo estaban preservadas.

En las lesiones completas del plexo braquial se investiga la existencia o no de raíces disponibles para utilizarlas como donantes de axones (transferencias intraplexuales). En caso de no existir, se recurre a las transferencias de nervios que no forman parte del plexo (transferencias extraplexuales) como pueden ser el nervio espinal accesorio, el nervio frénico, los nervios intercostales, etc. En caso de avulsión de todas las raíces, las transferencias extraplexuales son el único método de reinervación disponible.

La tasa de éxito de las neurotizaciones mejora si los fascículos del nervio donante coinciden con los del receptor en número axonal, tamaño y función lo más agonista posible; realizar la neurorrafia lo más cercana posible al músculo diana también es factor de buen pronóstico.

En este artículo vamos a revisar las técnicas quirúrgicas disponibles en el arsenal terapéutico de esa patología.

\section{Neurotizaciones Intraplexuales}

\section{Nervio Radial}

El nervio radial es el más comúnmente afectado en las lesiones del miembro superior. La parálisis radial puede ser resultado de gran variedad de causas como traumatismos directos, especialmente en las fracturas de la diáfisis humeral, compresiones, tumores, inflamación local, neuritis idiopática o lesión yatrogénica durante una cirugía. Puede afectarse de forma proximal, por una lesión de plexo braquial, o incluso distalmente en una lesión del nervio interóseo posterior.
El tratamiento de esas lesiones dependerá de la causa de la parálisis, la duración de los síntomas, y el nivel o extensión del déficit neurológico. Cuando no se asocia a lesiones abiertas, suele mantenerse una actitud expectante durante varios meses antes de una cirugía. Cuando existe una laceración o herida a menudo se requiere una exploración quirúrgica inmediata.

\section{Anatomía}

El cordón posterior del plexo braquial da lugar al nervio radial, con la contribución de las raíces C5-T1. El nervio radial baja alrededor de la diáfisis humeral por el canal espiral, tras lo cual pasa por debajo del vientre lateral del tríceps, sobre la superficie del septo intermuscular lateral. Inerva al braquiorradial y extensor carpi radialis longus antes de atravesar el codo y dividirse en el nervio interóseo posterior (NIOP) y el nervio radial superficial.

La rama superficial del nervio radial va por debajo el braquiorradial para inervar la zona radial del dorso de la muñeca y de la mano.

El NIOP rodea la cabeza del radio bajo el músculo supinador y sobre la membrana interósea. Inerva al extensor carpi radialis brevis, supinador, extensor común de los dedos, extensor propio del quinto dedo, extensor cubital del carpo, abductor largo del pulgar, extensores largo y corto del pulgar $\mathrm{y}$ al extensor propio del índice. El origen de la inervación del extensor carpi radialis brevis tiene gran variabilidad, pudiendo aparecer proximal a la formación del NIOP o junto con la rama sensitiva.

Por tanto, la lesión del nervio radial producirá un déficit de la extensión de los dedos y del pulgar, con una extensión radial de muñeca limitada, además de la afectación sensitiva.

\section{Transferencia del Nervio Musculocutáneo al Nervio Radial} Esa técnica fue descrita en 1947 por Lurje ${ }^{1}$, y fue diseñada para la reparación de defectos mayores de $6 \mathrm{~cm}$. Durante el procedimiento, se ha de localizar el nervio musculocutáneo en el espacio intersticial localizado entre el músculo bíceps y el braquial anterior una vez que ya ha dado las ramas al músculo coracobraquial, cuando se está ramificando para inervar al bíceps, habitualmente con 2 ó 3 ramas. En el tercio medio del brazo, el nervio dará de forma más o menos constante, una rama al músculo braquial anterior, mientras que en el tercio distal a veces proporciona 1 ó 2 ramas más para el mismo. En la flexura del codo, lateral al tendón bicipital, el nervio musculocutáneo da de forma ocasional una última rama para el músculo braquial, transformándose después en el nervio cutáneo antebraquial lateral. 

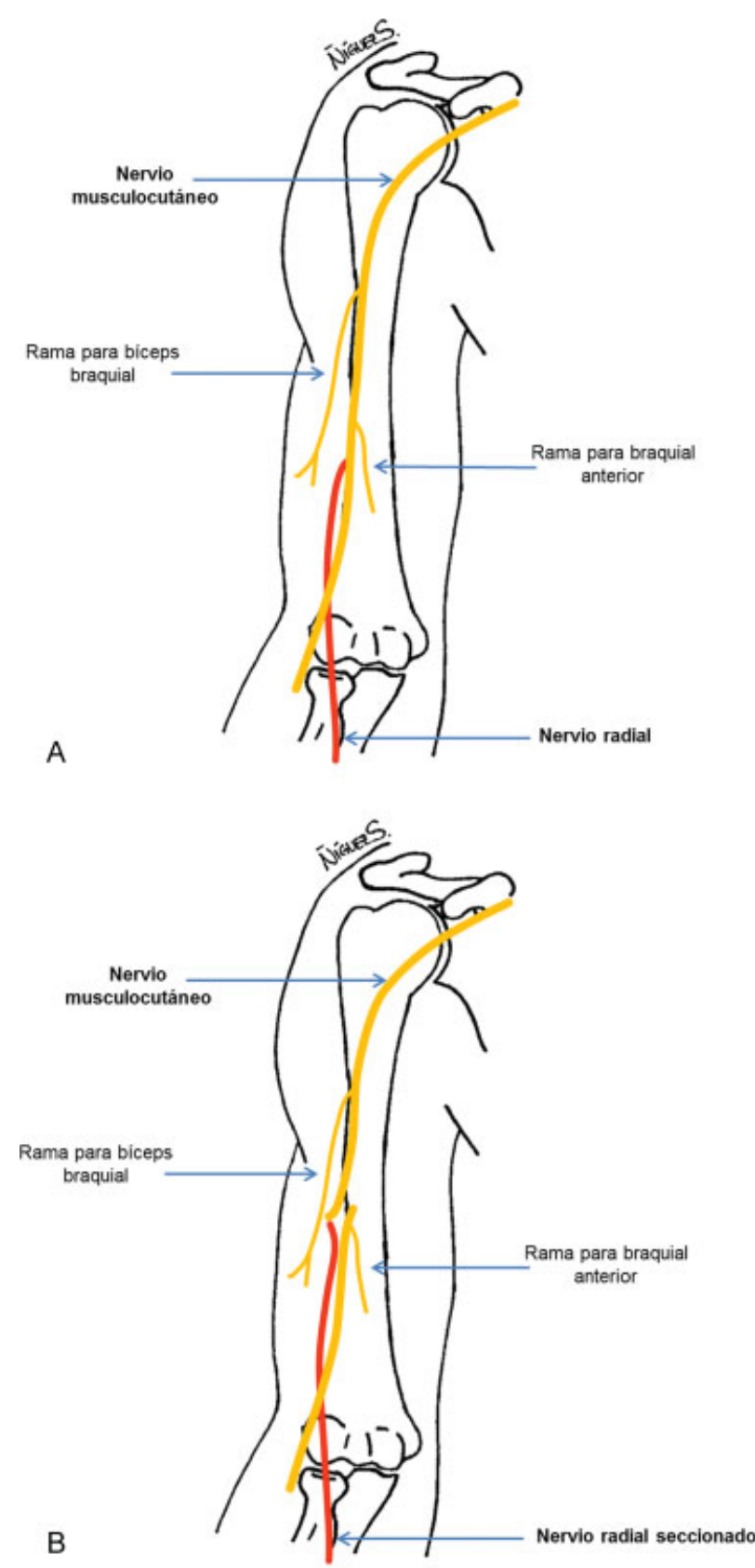

Fig. 1 (A) Anatomía del nervio radial y del nervio musculocutáneo. (B) Transferencia de nervio musculocutáneo, distal a la rama que inerva al bíceps braquial, al nervio radial.

El nervio musculocutáneo se secciona en la zona inmediatamente distal al origen de las ramas principales para el músculo bíceps, y proximal a las ramas distales del músculo braquial, por lo que no se afecta de forma considerable la flexión del codo. El bíceps, cuya inervación permanece intacta, compensará la función perdida por la denervación de parte del braquial. Es por ello que ese autor, considera que el nervio musculocutáneo, tras ser seccionado en el lugar indicado, puede ser utilizado para neurotizar el nervio radial mediante sutura término-terminal, en grandes defectos localizados en los dos tercios superiores del brazo o en la axila. (-Fig. 1)

Para llevar a cabo esta cirugía, es esencial que el extremo proximal de la sección del nervio radial esté localizado proximalmente a más de $6-7 \mathrm{~cm}$ del cóndilo lateral del húmero, para poder así realizar la sutura sin tensión.

Ese tipo de cirugía es especialmente útil cuando existe un gran defecto en el nervio radial acompañado de lesión del nervio mediano y cubital. En esos casos las transferencias tendinosas no son de utilidad.

Transferencia del Nervio Mediano al Nervio Radial: Ramas del Flexor Superficial de Los Dedos y del Palmar Menor El nervio mediano suele dar varias ramas al flexor superficial de los dedos a nivel del antebrazo, pudiéndose emplear una de ellas. Además, la rama del flexor carpi radialis (FCR) también puede ser transferida si se descarta su uso para futuras transferencias tendinosas.

Esa técnica fue descrita por Mackinnon y col. ${ }^{2}$ en el año 2002. Realizando un abordaje en la zona medial del antebrazo, se puede identificar el pronador redondo, retrayéndolo para visualizar el nervio mediano. Intraoperatoriamente se realiza una identificación topográfica sensitivomotora de todos los componentes del nervio mediano, llevando a cabo una neurolisis interna. Se localizan las ramas que inervan el flexor superficial de los dedos (FDS) del tercer y cuarto dígitos, al FCR y al palmar menor, apoyándose con el uso de neuroestimulador si es preciso.

También se identifican el NIOP y la rama del extensor carpi radialis brevis (ECRB). La neurotomía se realiza lo más proximal posible para facilitar su transferencia directa a la zona anterior del antebrazo. Las ramas nerviosas del FCR a veces junto a las del palmar menor son transferidas al NIOP y las del FDS son transferidas al ECRB. Previamente a la transferencia, hay que confirmar mediante electroestimulación, el correcto funcionamiento del pronador redondo, el nervio interóseo anterior, y las ramas el flexor profundo de los dedos. (-Fig. 2)

A pesar de que los autores presentan buenos resultados con esa técnica, hay que tener en cuenta que no sigue los principios de la sinergia muscular, ya que el donante utilizado para la extensión de la muñeca, es el flexor superficial de los dedos, que es un antagonista de los extensores. La selección de nervios donantes con funciones agonistas a los receptores, facilita la integración de los mismos. Además, el receptor para la extensión de muñeca es el ECRB, cuya inervación tiene una gran variabilidad en su origen, pudiendo proceder en el 50\% del NIOP, en el 30\% de la rama sensitiva del nervio radial y en el $20 \%$ de la bifurcación entre ellas. Eso unido a la difícil localización del vientre muscular, hace pensar que no es la mejor opción.

Como opción para neurotizar el NIOP también proponen que se puede emplear la rama del flexor cubital del carpo (FCU) dependiente del nervio cubital. ${ }^{2}$

Transferencia del Nervio Mediano al Nervio Radial: Ramas del Flexor Carpi Radialis y del Pronador Redondo

En 2014 se publicó una modificación a la descrita anteriormente, basada en la transferencia de una rama del pronador redondo (PR) al extensor carpi radialis longus (ECRL) para la extensión de la muñeca, y la rama del FCR al NIOP para restaurar la extensión de los dedos. ${ }^{3} \mathrm{Si}$ no existiese doble 
60 Técnicas de transferencia nerviosa en lesiones del miembro superior Martínez et al.
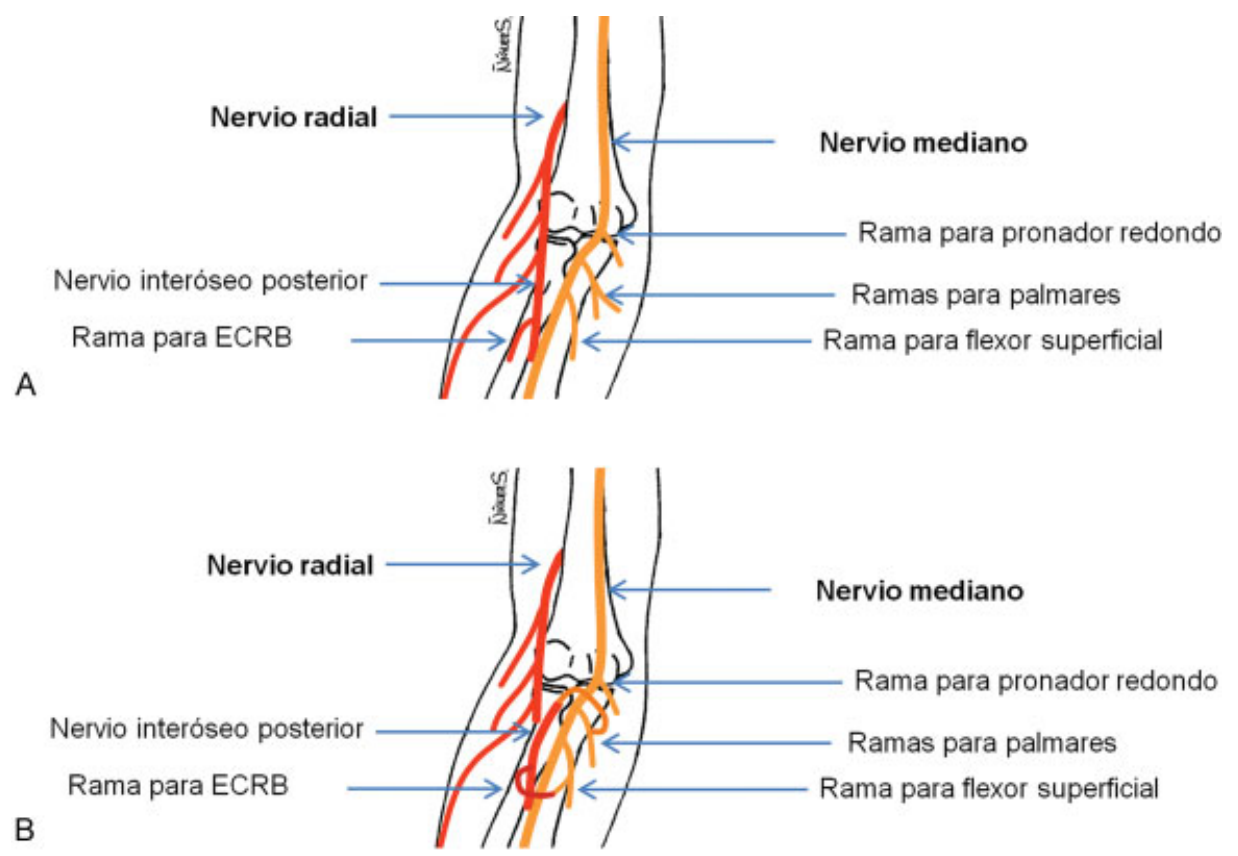

Fig. 2 (A) Anatomía del nervio radial y del nervio mediano. (B) Transferencia de la rama del FCR (nervio mediano) al NIOP (nervio radial), y de los fascículos para el tercer y cuarto dígitos del flexor superficial (nervio mediano) a la rama para el ECRB (nervio radial).

inervación del PR, se emplea entonces una rama del FDS para neurotizar el ECRL.

Mediante un único abordaje en la flexura del codo (-Fig. 3), se localiza el nervio radial en el intervalo entre el bíceps braquial y el braquiorradial. En la zona proximal del canal bicipital externo se localiza la rama nerviosa para el braquiorradial y la del ECRL. Se identifica el NIOP distalmente en la bifurcación con la rama sensitiva del nervio radial.

En la zona medial de la incisión, se expone el nervio mediano localizado en el canal bicipital interno y sus ramas para el pronador redondo (que suelen ser dos con una frecuencia cercana al 75\%) y la del FCR, que es la rama motora más larga en este nivel.
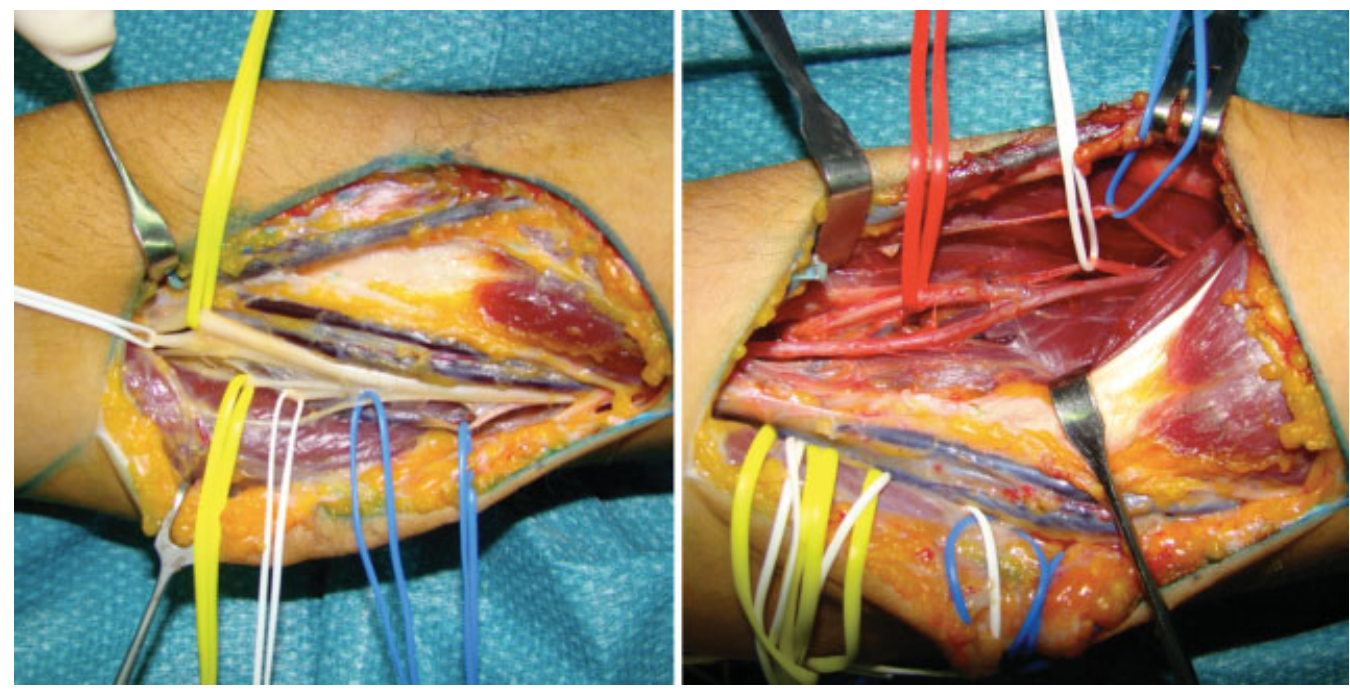

Fig. 3 A la izquierda se aprecia mediano dando ramas para pronador redondo (azul), flexores radiales de muñecan (blanco), flexor superficial (amarillo), hasta su división en Interóseo anterior (blanco) y resto del nervio mediano (amarillo). A la derecha se aprecia nervio radial dando ramas para Braquioradial (azul), ECRL (blanca), hasta su división en Interóseo posterior (rojo) y ramo sensitivo (sin cinta).
Entre las ramas que inervan el pronador redondo se elige la de mayor longitud, que suele ser la más proximal, se secciona en su entrada al pronador redondo y se dirige lateralmente para neurotizar la rama del ECRL, que se secciona también en su origen en el nervio radial, sin necesidad de disección intraneural.

La rama para el FCR se secciona en su entrada al músculo y se dirige lateralmente para unirla al NIOP, seccionada a nivel de la bifurcación con la rama sensitiva del nervio radial. (-Fig. 4)

\section{Nervio Mediano}

Las lesiones de las raíces C8-D1 del plexo braquial, conocido como Djerine-Klumpke, son lesiones poco comunes, cuyo 


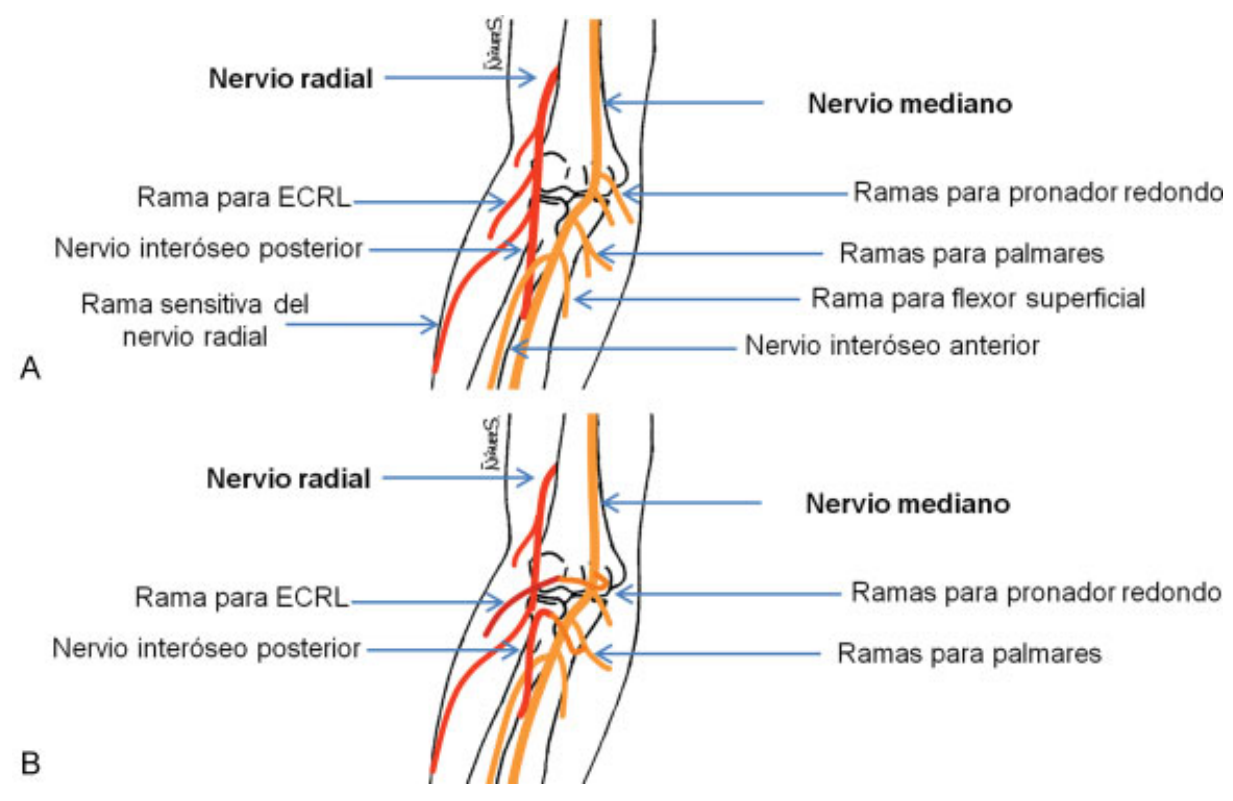

Fig. 4 (A) Anatomía del nervio radial y del nervio mediano. (B) Transferencia de una rama del pronador redondo (nervio mediano) a la rama del ECRL (nervio radial), y de la rama para el FCR (nervio mediano) al NIOP (nervio radial).

mecanismo de producción es una tracción con el brazo en abducción. Funcionalmente ese tipo de lesiones son equivalentes a una parálisis mediana y cubital alta, con pérdida sensitiva en el territorio del nervio cubital.

Suelen estar dañados los grupos fasciculares posterior y medial, con preservación del grupo anterior, principalmente motor, que inerva al pronador redondo y al FCR. El grupo fascicular medial lleva las fibras sensitivas, que suelen mantenerse indemnes, y las fibras motoras de la mano, cuyos músculos quedan paralizados. Por último, el grupo fascicular posterior es principalmente motor y contiene las fibras del nervio interóseo anterior (NIOA).

La prioridad en el tratamiento de ese tipo de lesiones, es recuperar la flexión de los dedos, por lo que el grupo fascicular posterior será el receptor de las transferencias.

\section{Anatomía}

El nervio mediano está formado por la unión de las divisiones del fascículo lateral (C5-C7) y medial (C8-T1) del plexo braquial. Desciende por el brazo junto a la arteria braquial, siguiendo hacia la fosa cubital lateral al tendón del bíceps, y pasando al antebrazo entre las dos cabezas del pronador redondo. Seguidamente, cruza la arcada tendinosa y se sitúa entre los flexores comunes superficial y profundo de los dedos, unido a la superficie profunda del primero. En el antebrazo inerva al pronador redondo, palmar mayor $\mathrm{y}$ menor, y flexor superficial de los dedos. Después emerge el NIOA que, junto a la arteria interósea, se sitúa entre el flexor profundo de los dedos, al que inerva en su mitad radial correspondiente a los dedos $2^{\circ}$ y $3^{\circ}$ (y ocasionalmente al $4^{\circ}$ ), y al flexor largo del pulgar, al que también dará una rama. Finalmente inerva al pronador cuadrado. Del tronco principal sale una rama cutánea palmar antes de entrar en el túnel del carpo. Una vez que el nervio cruza el túnel inerva al abductor corto, oponente y flexor corto del pulgar, así como a los lumbricales I y II y acaba dando las ramas sensitivas terminales.

En 2004-2005, Zhao y col. ${ }^{4,5}$ documentaron la existencia de los tres grupos fasciculares en el nervio mediano que se han explicado con anterioridad, siendo los primeros en describir la disección de los mismos para la transferencia del nervio frénico de forma selectiva al grupo fascicular posterior.

Para la identificación fascicular, el nervio se localiza en el canal bicipital interno, entre el bíceps y el tabique intermuscular medial o el músculo braquial. A nivel del codo, la fascia antebraquial, el lacertus fibroso y la aponeurosis bicipital son seccionados para facilitar la movilización del nervio.

Tras eso se puede realizar una disección de los tres grupos fasciculares:

- El grupo anterior está compuesto por las ramas del pronador redondo y el FCR: suele haber dos ramas para el pronador y una para el FCR, que surgen a modo de tridente a unos $4 \mathrm{~cm}$ sobre el cóndilo medial.

- El grupo fascicular posterior está compuesto mayormente por las ramas del NIOA, palmar menor y algunas ramas finas de la zona proximal de los flexores superficial y profundo de los dedos. Su origen se puede localizar entre el borde lateral de la cabeza superficial del pronador redondo, y el borde medial del braquiorradial. La primera de ellas será la del palmar menor, seguida por el NIOA.

- El grupo fascicular medial está formado por la mayoría de las ramas de los músculos de la mano y el flexor superficial de los dedos. Constituye la mayor parte del nervio mediano en la zona más distal del brazo, cuando los fascículos anterior y posterior ya han dado sus ramas.

En la práctica sólo es necesario localizar el fascículo posterior, aunque en ocasiones también se puede reparar el grupo fascicular medial. 


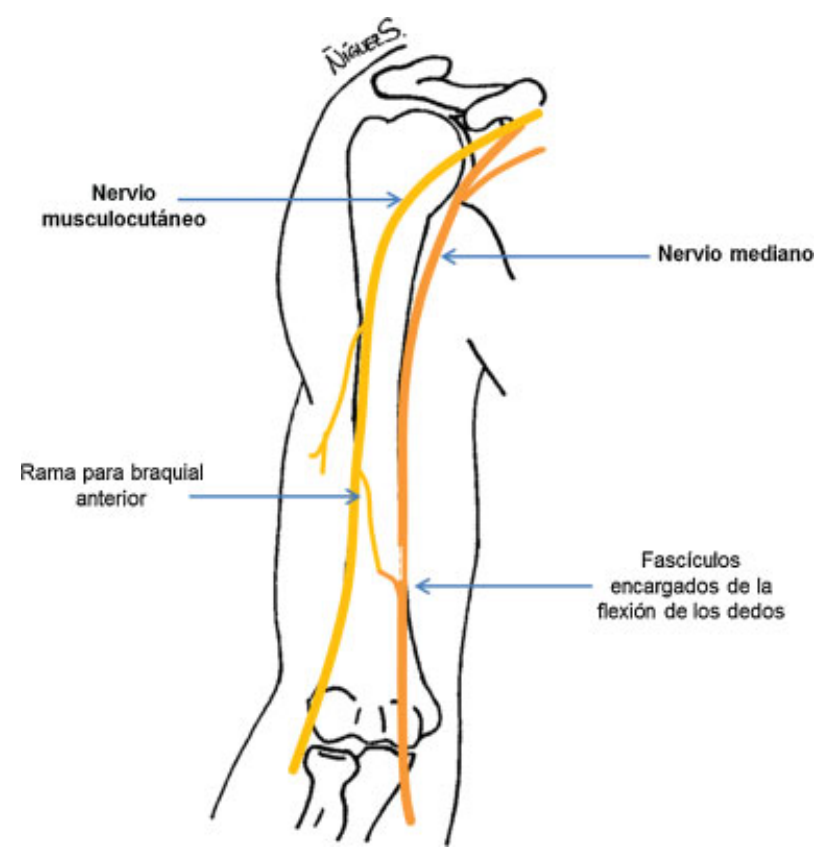

Fig. 5 Transferencia de la rama del nervio musculocutáneo que inerva al braquial anterior, al fascículo posterior del nervio mediano encargado de la flexión de los dedos.

Transferencia del Nervio Musculocutáneo al Nervio Mediano: Rama del Braquial Anterior

En $2004 \mathrm{Gu}$ y col. ${ }^{6}$ describieron la transferencia de la rama que da el nervio musculocutáneo para el músculo braquial anterior al fascículo posterior del nervio mediano encargado de la flexión de los dedos para restaurar esa función. En su estudio anatómico mostraron tres variantes anatómicas: la existencia de una sola rama para dicho músculo (la variante más común), la presencia de dos ramas (una proximal más gruesa y una distal más fina), y un patrón múltiple con más de dos ramas.

Ese procedimiento se realiza mediante una incisión única en la zona medial del brazo. Se expone el nervio musculocutáneo, localizando la rama para el braquial a unos $13 \mathrm{~cm}$ del cóndilo medial, diseccionándose aproximadamente $4 \mathrm{~cm}$ de la misma. El nervio mediano se identifica medial al musculocutáneo, y se realiza una disección intraneural para localizar, en su zona posterior, el fascículo que se encargará de la flexión de los dedos. Dicha disección se amplía hasta que los fascículos puedan trasladarse sin tensión. (-Fig. 5)

Ese procedimiento tiene una serie de ventajas: en primer lugar, se realiza con una sola incisión siendo relativamente fácil y poco traumático; y en segundo lugar, que la unión del nervio donante y el receptor se realiza termino-terminal sin tensión. Por otra parte, los inconvenientes son que está lejos de los músculos diana, que se debe confiar en la distribución anatómica intraneural y que se sacrifica un músculo flexor primario de codo.

Transferencia del Nervio Radial al Nervio Mediano: Rama del Braquiorradial al Interóseo Anterior.

En 2001 se describió una técnica que consistía en la transferencia directa de la rama que el nervio radial da al músculo braquiorradial, al NIOA. $^{7}$

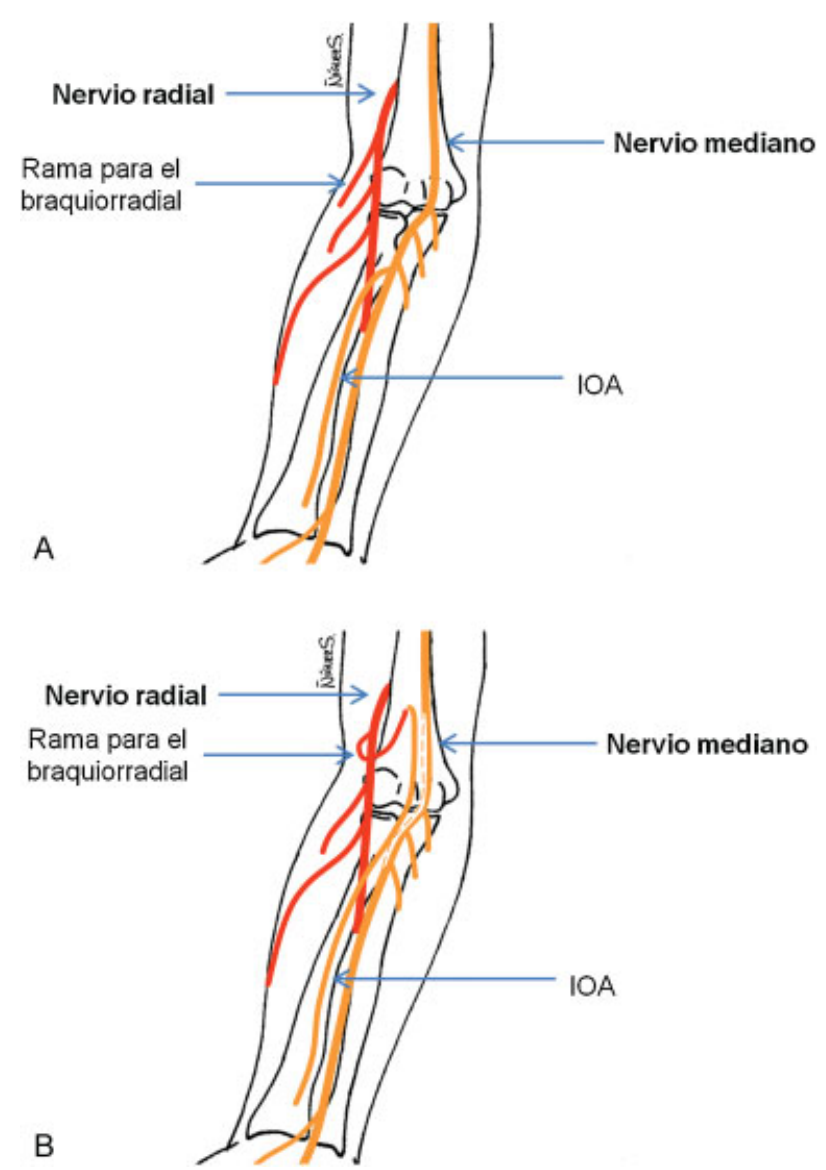

Fig. 6 (A) Anatomía del nervio radial y del nervio mediano. (B) Transferencia de la rama nerviosa para el braquiorradial (nervio radial) al nervio interóseo anterior (nervio mediano).

Para ello se realiza una incisión en la zona de la flexura del codo. El nervio radial se localiza en su entrada en el canal intersticial existente entre el bíceps y el braquiorradial. En la zona más proximal del canal se localiza y se estimula la rama del braquiorradial.

El nervio mediano se identifica en la profundidad del canal bicipital interno, junto al pedículo vascular. La disección del nervio mediano se extiende, proximalmente hasta la unión del tercio medio y distal del brazo, y distalmente entre las dos cabezas del músculo pronador redondo, hasta la aparición del NIOA y su entada en la arcada del flexor superficial de los dedos.

Se moviliza el NIOA proximalmente mediante disección interfascicular; esa disección puede alcanzar fácilmente el tercio distal del brazo en la zona posterior del nervio mediano, $1 \mathrm{~cm}$ proximal al origen de la rama del braquiorradial. Esa última se seccionará cerca de su entrada al músculo, y será transferida al NIOA. (-Figs. 6 y 7)

Una de las principales ventajas de esa técnica es el uso de una rama nerviosa que inerva un músculo accesorio para la flexión y la supinación del antebrazo cuando el brazo está en pronación máxima. Por tanto, su denervación no causará una impotencia funcional significativa. Además, la transferencia al NIOA puede realizarse más distalmente que las técnicas propuestas previamente, y por tanto, estará más cerca del 


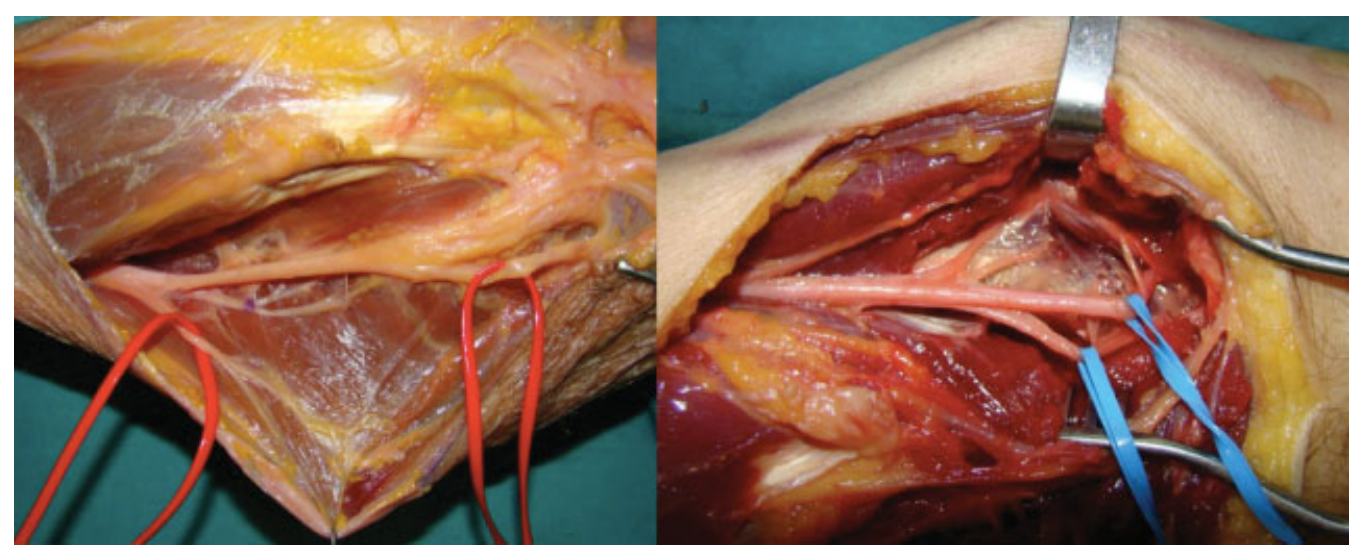

Fig. 7 A la izquierda se aprecia nervio radial dando ramas para Braquioradial (rojo), ECRL (sin cinta), hasta su división en Interóseo posterior (sin cinta) y ramo sensitivo (rojo). A la derecha se aprecia la salida del Interóseo anterior (azul) en la zona posterior del mediano después de haber dado este las ramas para pronador, radiales y flexor superficial.

músculo diana, facilitando su reinervación y la recuperación de la movilidad. En tercer lugar, puede llevarse a cabo mediante una sola incisión, siendo una técnica sencilla y reproducible, permitiendo la recuperación de la flexión de los tres primeros dígitos.

\section{Nervio Cubital}

Las lesiones del nervio cubital pueden ser muy limitantes, provocando debilidad para la flexión de la muñeca, pérdida de la función intrínseca de la mano, y afectación sensitiva en el lado cubital de la mano.

Las lesiones proximales al codo suelen ser de origen traumático, y su abordaje sería similar al del nervio mediano. Por otro lado, el atrapamiento del nervio cubital en el codo es el segundo síndrome de atrapamiento más frecuente después del síndrome del túnel carpiano (nervio mediano), siendo la clínica similar a la descrita en lesiones proximales, aunque es característico el dolor en el codo. Cuando la lesión del nervio es en el antebrazo, se preserva el flexor cubital del carpo. La compresión a nivel de la muñeca y la mano es el segundo punto más frecuente de compresión del nervio cubital, pudiendo haber una lesión completa (alterando la sensibilidad y existiendo debilidad de la musculatura de la mano), o parcial. La lesión aislada de la rama dorsal sensitiva puede ser traumática o compresiva. Tanto las lesiones proximales como las distales, en su evolución, se manifiestan con la característica mano en garra por debilidad de interóseos y lumbricales.

\section{Anatomía}

El nervio cubital se origina del fascículo medial del plexo braquial (C8-D1). Es un nervio mixto que discurre en el brazo junto al nervio mediano y medial a la arteria braquial, pasando a través del tabique aponeurótico medial al compartimento posterior, y siguiendo hasta el canal cubital en el codo. Al llegar al codo da las primeras ramas al músculo flexor cubital del carpo y la parte del flexor profundo de los dedos correspondientes al cuarto y quinto dígitos. Pasa a través de las cabezas humeral y cubital del músculo flexor cubital del carpo, situándose bajo el flexor profundo de los dedos hasta la muñeca, donde da ramas sensitivas para la eminencia hipotenar, la zona cubital del dorso de la mano, y para los dedos cuarto y quinto. Llega al canal de Guyon entre los huesos pisiforme y ganchoso, para seguir como nervio motor de los músculos de las eminencias hipotenar y tenar, músculos interóseos y lumbricales.

En la exploración observamos el signo de Froment por debilidad del aductor del pulgar, la atrofia de los músculos interóseos, sobre todo el primero dorsal, y de la eminencia hipotenar. La sensibilidad estará alterada en el quinto dedo y mitad cubital del cuarto, así como la mitad cubital de la palma y dorso de la mano hasta la muñeca.

\section{Transferencia del Nervio Mediano al Nervio Cubital: Interóseo Anterior a la Rama Motora del Cubital}

La transferencia del NIOA a la rama motora del nervio cubital para restaurar la función intrínseca de la mano fue llevada a cabo por primera vez en 1991 por Mackinnon, ${ }^{8,9}$ siendo descrita posteriormente por otros autores con leves variaciones, ya que es la única que ha conseguido la reinervación de la musculatura intrínseca de la mano. (-Fig. 8)

El abordaje se realiza 6-7 $\mathrm{mm}$ cubital al pliegue tenar de la mano, procediendo a la apertura del canal de Guyon, realizando una disección cuidadosa para evitar la sección de las ramas cutáneas palmares de los nervios mediano y cubital. Al llegar al pliegue de la muñeca, el abordaje se aumenta a proximal realizando una incisión en zigzag. Conforme se avanza se va liberando el nervio cubital a proximal y se realiza la apertura de la fascia antebraquial así como del músculo palmar corto si está presente. Una vez que el ligamento está abierto, se separa el paquete neurovascular a medial para permitir la exposición del nervio cubital en la mano. Es necesario palpar el gancho del ganchoso para orientarse, ya que es en ese lugar donde la rama motora profunda del cubital se refleja a radial y dorsal, situándose bajo la musculatura hipotenar. A continuación, se identifica la fascia muscular de la eminencia hipotenar y se sigue proximalmente hasta el borde libre de la misma, justo en la zona cubital al gancho del ganchoso. Es en ese punto, donde la rama motora del cubital se separa del resto del 


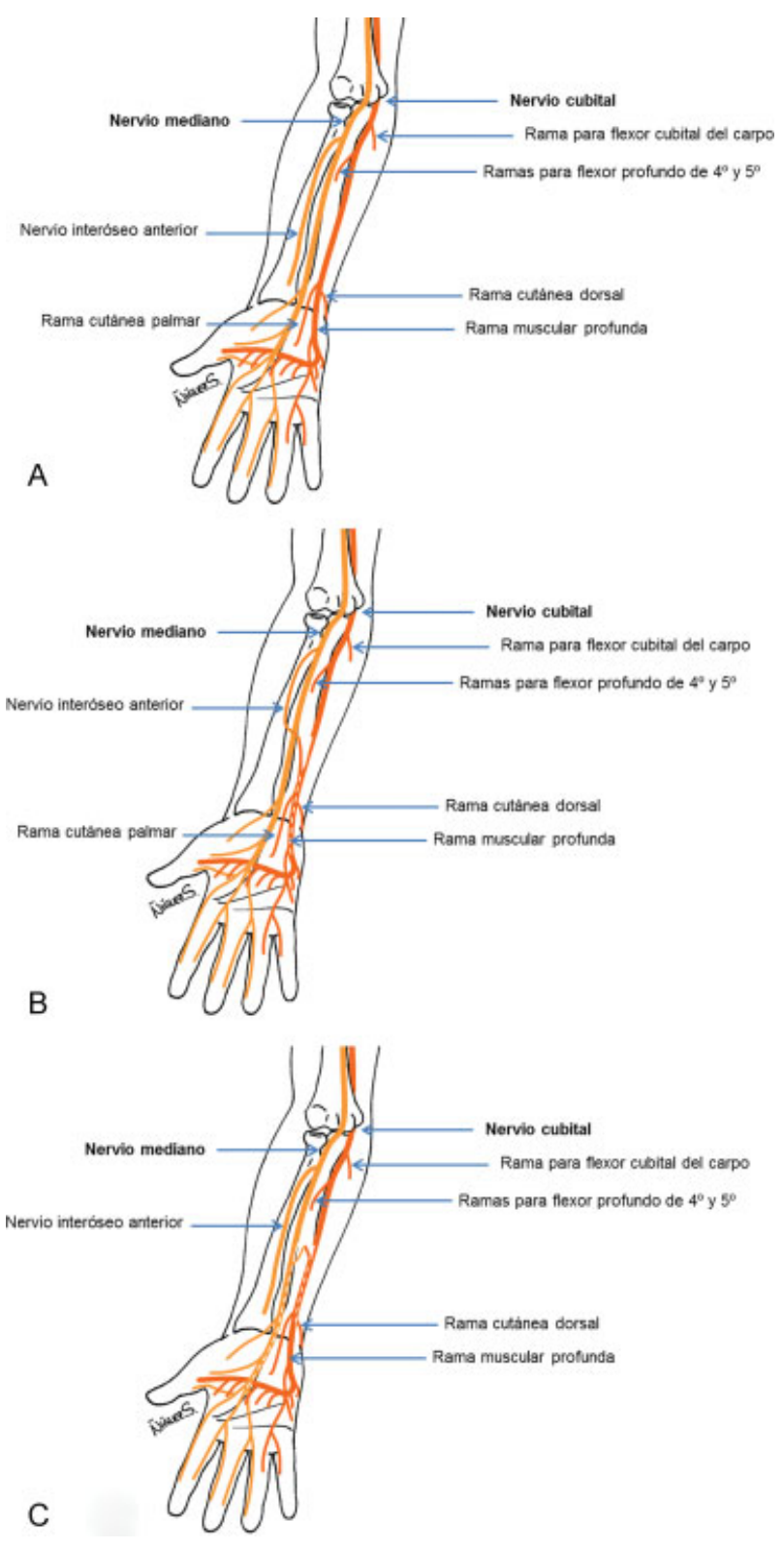

Fig. 8 (A) Anatomía del nervio mediano y del nervio cubital. (B) Transferencia del NIOA (nervio mediano) a la rama motora del nervio cubital. (C) Transferencia de la rama sensitiva para el tercer espacio interdigital (nervio mediano) a la rama cutánea dorsal del nervio cubital.

nervio. Una vez hallada, se descomprime la rama hasta llegar al flexor propio del quinto dedo. Es muy importante liberar el nervio hasta el borde libre de la fascia hipotenar para conseguir una buena regeneración nerviosa. ${ }^{10}$ En ese punto, se volverá a comprobar, mediante estimulación nerviosa, el déficit de respuesta por parte de esa rama motora.

Seguidamente se extiende la incisión a proximal, siguiendo el nervio cubital en el antebrazo y localizando la división entre el grupo fascicular motor y el sensitivo. Ese último se encontrará en el lado radial del nervio cubital. El fascículo correspondiente a la rama motora del nervio cubital descansa en el lado cubital del componente sensitivo, y la rama cutánea dorsal estará en el lado cubital de la rama motora (quedando una disposición sensitiva-motora-sensi- tiva). En ocasiones, existe un pequeño vaso sanguíneo dispuesto en el epineuro de forma longitudinal marcando la división entre los distintos componentes. Se realiza la disección nerviosa intraneural desde el ganchoso hasta la zona proximal, donde se seccionará sólo el fascículo motor, para evitar así manipulaciones innecesarias del nervio y reducir el tiempo quirúrgico (-Fig. 9).

El NIOA se puede encontrar profundamente en la zona central del antebrazo, junto con su vaso acompañante, entrando en el músculo pronador cuadrado. En primer lugar, se identificará el pronador separando los tendones flexores a radial para identificar el músculo hasta la zona más cubital. El paquete neurovascular se puede identificar en la zona proximal y central del músculo. Cuidadosamente se separa el nervio del paquete y se sigue en el interior del músculo para ganar varios centímetros de longitud. El nervio empieza a dar ramas en la porción central del músculo, y es en ese punto donde se seccionará y movilizará proximalmente para transferirlo al nervio cubital. De forma similar a como se secciona el NIOA en la zona más distal, es muy importante que la rama motora del nervio cubital se seccione suficientemente proximal para que pueda ser movilizada y unida al NIOA sin tensión en ninguna posición de la muñeca o los dedos. Ese punto suele localizarse a unos $9-10 \mathrm{~cm}$ proximales a la muñeca. Con esa técnica se obtienen resultados satisfactorios, a pesar de que el NIOA contiene menos fibras nerviosas que la rama motora profunda del cubital.

También se puede recuperar la sensibilidad grosera realizando trasferencia de la rama palmar cutánea del mediano al fascículo sensitivo del borde cubital de la mano que se encuentra en la parte más radial del nervio, teniendo en cuenta que la recuperación puede aparecer incluso a los dos años de la transferencia. ${ }^{11}$ Un traumatismo prolongado en una zona anestesiada debido a la denervación puede llevar a la ulceración de la piel y otras comorbilidades. Para evitar eso, es recomendable asociar una transferencia sensitiva a la reparación motora.

La reinervación sensitiva cubital también se puede conseguir mediante una transferencia termino-terminal del fascículo del tercer espacio interdigital, inervado por el nervio mediano. Una vez localizado el nervio mediano en la zona distal del antebrazo, el componente sensitivo del tercer espacio interdigital se puede identificar de forma similar a como se ha hecho anteriormente con el nervio cubital, ya que existe un plano delimitado por un vaso sanguíneo. Si ese plano no se pudiese identificar claramente, habría que seguir el nervio mediano hacia la mano mediante la apertura completa del ligamento anular anterior del carpo, para así poder identificar las ramas cuando empiezan a separarse del componente principal del nervio. La rama motora se seguirá proximalmente hasta el antebrazo, sin necesidad de realizar la neurolisis de la misma, como hemos explicado en el caso de la rama motora cubital. La rama sensitiva del nervio mediano se secciona distalmente, proximal al límite proximal del túnel carpiano, para asegurar una unión sin tensión. Ese fascículo se lleva entonces proximalmente para transferirlo al componente sensitivo del nervio cubital. Se recomienda hacerlo a unos 5-6 cm proximales a la muñeca para evitar la articulación. 


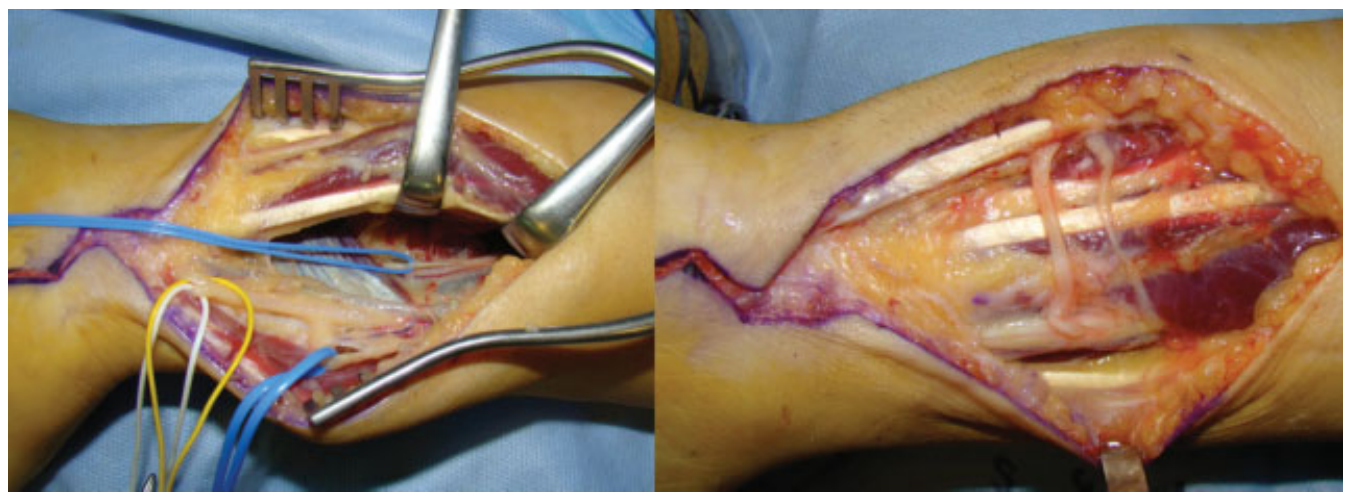

Fig. 9 A la izquierda se aprecia como el Interóseo anterior (azul) se introduce en el pronador cuadrado, en la parte inferior se aprecia división fascicular del cubital en rama sensitiva dorsal(azul), rama motora (blanco) y rama sensitiva (amarillo). A la derecha imagen de doble trasferencia nerviosa: interóseo anterior a rama motora y palmar cutáneo a rama sensitiva.

\section{Nervio Musculocutáneo}

La flexión del codo es la función a restaurar más importante en un brazo paralítico. El músculo braquial anterior es el principal flexor del codo, mientras que el bíceps es un músculo supinador que, de forma secundaria, colabora en la flexión. De esa manera, la lesión completa del nervio musculocutáneo produce una debilidad importante de la flexión del codo, especialmente con el brazo en supinación, y alteración de la sensibilidad en el borde radial del antebrazo.

Al contrario del nervio radial, la parálisis aislada del nervio musculocutáneo es rara. Puede producirse de forma excepcional en traumatismos y fracturas humerales. De forma más frecuente pueden producirse compresiones a su paso por el músculo coracobraquial con determinadas prácticas deportivas.

\section{Anatomía}

El nervio musculocutáneo surge de la división externa del fascículo lateral del plexo braquial (C5-C7). Perfora el músculo coracobraquial, inervándolo, y de ahí pasa al plano intermuscular existente entre el bíceps y el braquial anterior, a los que inerva. Posteriormente sale de la fascia del braquial anterior, y en el antebrazo se hace subcutáneo, dando lugar al nervio cutáneo antebraquial lateral, que inerva el borde radial de la cara anterior del antebrazo.

Por tanto, la lesión del nervio musculocutáneo producirá un déficit de la flexión del codo, además de reducir la fuerza supinadora que aporta el bíceps braquial, y un déficit sensitivo que suele ser menor del esperado, debido a las anastomosis que presenta con la rama sensitiva del nervio radial.

Transferencias de los Nervios Cubital y Mediano al Nervio Musculocutáneo

Ese procedimiento fue descrito en 1994 por Oberlin y col. ${ }^{12}$, relatando la transferencia de un fascículo del nervio cubital a la rama bicipital del nervio musculocutáneo. Dada la gran potencia flexora del músculo braquial, esa técnica fue modificada en el 2003 por Mackinnon y col. ${ }^{13}$, quienes desarrollaron una transferencia de dos fascículos, utilizando ramas de los nervios mediano y cubital para reinervar las ramas del nervio musculocutáneo para el bíceps y el braquial anterior.
El abordaje se realiza en la porción central del canal bicipital, diseccionando el intervalo entre el tríceps y el bíceps. El nervio cubital se localiza medial a la arteria braquial, mientras el mediano se encuentra lateral a la misma. El nervio musculocutáneo se identifica en la superficie profunda y medial del bíceps, previa palpación. La rama o ramas para el bíceps se originan en la zona más proximal y transcurren más laterales, mientras que la rama o ramas para el braquial anterior surgen distalmente y se dirigen más mediales profundizando en el músculo. Ambas se seccionan en la zona proximal, en su punto de origen, y se llevan a la zona medial donde se unen al nervio mediano y cubital. El fascículo donante se selecciona por proximidad, aunque generalmente la rama bicipital queda cerca del nervio mediano, y la rama del braquial, del nervio cubital (-Figs. 10 y 11). Usando un estimulador nervioso se identificarán los fascículos predominantemente flexores de muñeca, los del nervio mediano que inervan el FCR y los del nervio cubital para el flexor cubital del carpo(FCU). Alternativamente se puede usar como donante del nervio mediano, fascículos del flexor superficial de los dedos y del pronador redondo.

En la actualidad está muy discutido que sea necesaria esa doble neurotización y se aconseja realizar una sola de un fascículo flexor de muñeca a una rama del bíceps braquial. Con esa neurotización aislada, se consigue buena flexión de codo y se evita el déficit motor que suele quedar tras el empleo de un fascículo del mediano.

\section{Neurotizaciones Extraplexuales}

\section{Nervio Espinal Accesorio}

Es una de las transferencias nerviosas más populares y la primera descrita en la literatura, en 1913 por Tuttle. ${ }^{14}$ Se usa sobre todo para neurotizaciones del nervio del supraescapular. Se aborda en el triángulo posterior del cuello, encontrándose el nervio en la superficie anterior del músculo trapecio. Se puede iniciar la búsqueda de la zona proximal del nervio en la unión entre los tercios superior y medio del músculo esternocleidomastoideo, y su parte distal en la unión de los tercios medio e inferior del trapecio, ${ }^{15} \mathrm{sin}$ embargo existen otras técnicas para su localización. ${ }^{16}$ 


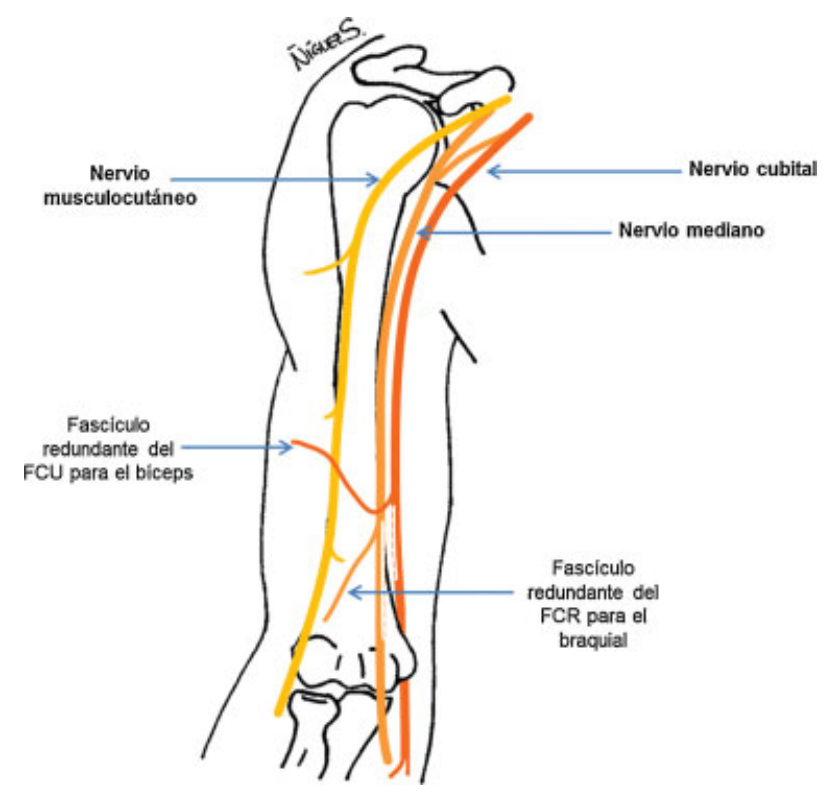

Fig. 10 Trasfererncia para el nervio musculocutáneo. Fascículo prodominantemente flexor de muñeca (FCU) del cubital para biceps braquial. Fascículo predominantemente flexor de muñeca (FCR) del mediano para braquial anterior.

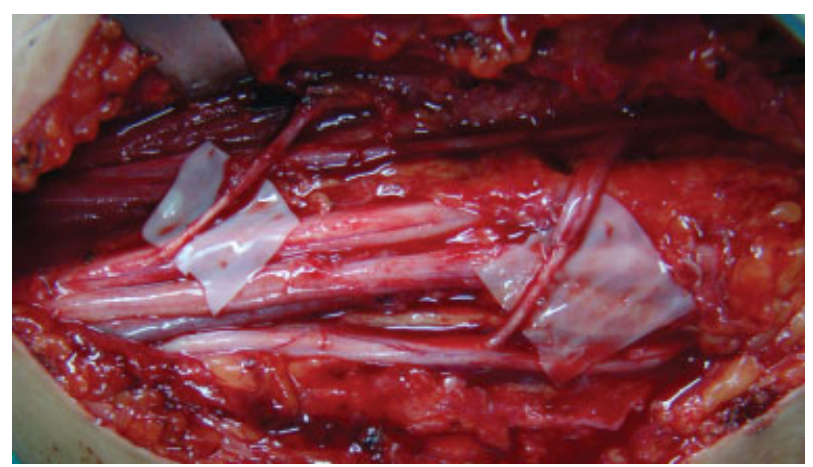

Fig. 11 Doble trasferencia nerviosa para musculocutáneo: a la izquierda fascículo de mediano a bíceps y la derecha fascículo de cubital a braquial anterior. Entre mediano y cubital se encuentra la arteria braquial.

Bertelli y Ghizoni ${ }^{17}$ describieron la que posiblemente sea la técnica más sencilla y fiable para la recolección del nervio espinal accesorio en el cuello. En el margen anterior del trapecio se separa la fascia cervical del músculo en una zona proximal a la clavícula $3-4 \mathrm{~cm}$, ya que es ahí donde el nervio accesorio es más superficial y por tanto, más fácilmente identificable. Visualizar las ramas motoras entrando en el músculo puede ayudar en su localización. Antes de seccionarlo es recomendable estimularlo eléctricamente para asegurar su integridad. Se seccionará tan distalmente como sea necesario para conseguir el contacto directo con el nervio receptor sin tensión. Si se desinserta el trapecio se puede diseccionar el nervio hasta el ángulo superior y medial de la escápula. Posteriormente se reinsertará el trapecio en la clavícula y el acromion.

\section{Nervio Frénico}

Se usa para neurotizaciones del nervio supraescapular, musculocutáneo y del nervio mediano. En la literatura se

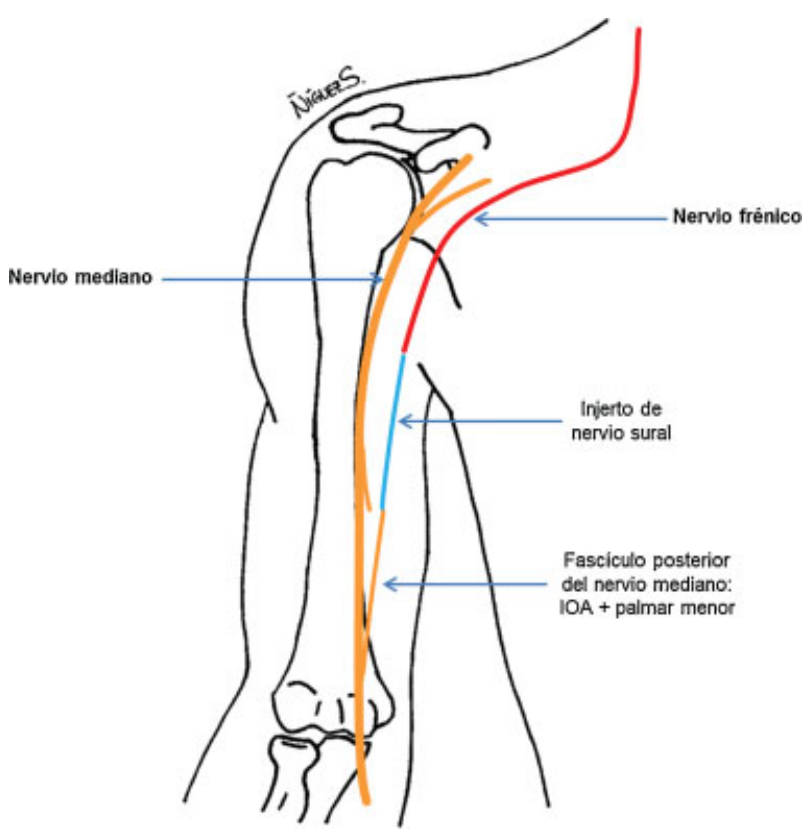

Fig. 12 Transferencia de nervio frénico a fascículo posterior del nervio mediano, con injerto de nervio sural.

han descrito buenos resultados para el tratamiento de las lesiones del plexo braquial, aunque no debe ser usado como donante para reconstrucciones en niños menores de un año, o cuando se usen intercostales simultáneamente. Este nervio se localiza de forma constante en la cara anterior del músculo escaleno anterior, con una trayectoria de lateral a medial, empleando un abordaje supraclavicular, y disecando el nervio proximalmente hasta la aparición de la raíz $\mathrm{C} 5,{ }^{15}$ aunque su abordaje varía según el nervio al que vaya a transferirse.

\section{Transferencia del Nervio Frénico al Nervio Mediano} Descrita en 2004-2005, Zhao y col. ${ }^{4,5}$ Antes de abordar el nervio frénico, se realizan radiografías de tórax en inspiración y espiración máximas para excluir una posible lesión del nervio. También se realizan test de función pulmonar y un electrocardiograma. La incisión se lleva a cabo sobre la quinta costilla, desde la línea medioaxilar hasta la zona lateral del esternón. Se abre el periostio inferior de la costilla así como la pleura adherida, para alcanzar el pericardio, en cuyo lateral se encuentran el nervio frénico y la arteria y vena pericardiofrénicas. El nervio se va separando de la pleura para poder movilizarlo, desde su entrada en el diafragma, donde se seccionará, hasta el ápex de la cavidad torácica. Se realiza una nueva incisión entre línea axilar anterior y el segundo espacio intercostal, y una tercera en la axila, desde donde se recuperará el nervio. Desde la incisión axilar hasta el brazo se pasará el nervio a través del tejido subcutáneo. Una vez trasladado se medirá el gap existente entre el extremo del nervio frénico y el NIOA, y se tomará un injerto de nervio sural para hacer de conexión entre ambos (-Fig. 12).

Esa trasferencia nerviosa es muy poco utilizada en la actualidad. 


\section{Nervios Intercostales}

Se han utilizado especialmente para neurotizaciones del nervio musculocutáneo. Se deben realizar sin injerto interpuesto para obtener un mejor resultado, por lo que hay que hacer la disección lo más distalmente posible. El abordaje se realiza a lo largo del borde inferior del pectoral mayor desde el pliegue axilar anterior hacia el esternón. Se diseca y se rechaza el pectoral mayor hacia arriba. El pectoral menor se encuentra debajo, y se usa su borde lateral como punto de referencia para identificar la tercera, cuarta y quinta costillas, que se desperiostizan, identificando el nervio en el borde inferior de la costilla a nivel de los músculos intercostales. ${ }^{14}$

\section{Raíces Cervicales Superiores}

Se emplean los ramos anteriores primarios de las raíces cervicales C3 y C4 (ambos o uno solo), inmediatamente distales al nervio frénico. Esa transferencia está especialmente indicada en parálisis del plexo braquial obstétrico. Se realiza una incisión en el borde posterior del músculo esternocleidomastoideo para exponer el plexo supraclavicular, y se disecciona la raíz C3 y C4 a nivel foraminal. La disección ha de ser muy cuidadosa, con estimulación eléctrica, dada la gran variación existente en la anatomía del plexo braquial. ${ }^{18}$

\section{Raíz C7 Contralateral}

La raíz C7 inerva redundantemente a los músculos también nutridos por las raíces $\mathrm{C} 8$ y D1, por lo que se ha propuesto usar C7 del lado sano como dador de axones al plexo paralizado. El sacrificio de esa raíz implica una parálisis del tríceps muy leve, clínicamente no evidente en la mayoría de los casos. ${ }^{19}$ Es necesario diseccionar la raíz de C7 sana contralateral con un abordaje cervical anterior, así como el nervio lesionado, y el nervio cubital con su pedículo vascular hasta la muñeca, puesto que se utiliza como injerto colocándolo en un túnel subcutáneo entre la raíz C7 contralateral y el nervio que va a ser neurotizado. ${ }^{15}$ Es una técnica compleja con múltiples riesgos asociados, por lo que su uso ha quedado reservado en pacientes muy seleccionados con lesiones concomitantes del nervio frénico y el espinal accesorio.

\section{Nervio Hipogloso}

Se obtienen pobres resultados funcionales con la transferencia del nervio hipogloso al plexo braquial, mientras que las anastomosis hipogloso-facial suelen ser existosas. Se realiza mediante una incisión que comienza $2 \mathrm{~cm}$ posterior y $2 \mathrm{~cm}$ por debajo del gonion (punto de unión entre el ramo ascendente y el cuerpo de la mandíbula), y se extiende hacia el distal en la región submaxilar. Se disecciona el platisma y se identifica el vientre anterior del músculo digástrico. Inferior a ése se encuentra el músculo hipogloso, muy cerca de la arteria carótida. ${ }^{15}$

Conflictos de interese

Los autores no declaran ningún conflictos de interese.

\section{Bibliografía}

1 Lurje AS. On the use of $n$. musculocutaneous for neurotization of n. radialis in cases of very large defects of the latter. Ann Surg 1948;128(01):110-115

2 Lowe JB III, Tung TR, Mackinnon SE. New surgical option for radial nerve paralysis. Plast Reconstr Surg 2002;110(03):836-843

3 García-López A, Navarro R, Martínez F, Rojas A. Nerve transfers from branches to the flexor carpi radialis and pronator teres to reconstruct the radial nerve. J Hand Surg Am 2014;39(01):50-56

4 Zhao X, Lao J, Hung LK, Zhang GM, Zhang LY, Gu YD. Selective neurotization of the median nerve in the arm to treat brachial plexus palsy. An anatomic study and case report. J Bone Joint Surg Am 2004;86-A(04):736-742

5 Zhao X, Lao J, Hung LK, Zhang GM, Zhang LY, Gu YD. Selective neurotization of the median nerve in the arm to treat brachial plexus palsy. Surgical technique. J Bone Joint Surg Am 2005; 87(Pt 1, Suppl 1)122-135

6 Gu Y, Wang H, Zhang L, Zhang G, Zhao X, Chen L. Transfer of brachialis branch of musculocutaneous nerve for finger flexion: anatomic study and case report. Microsurgery 2004;24(05): 358-362

7 García-López A, Sebastian P, Martínez F, Perea D. Transfer of the nerve to the brachioradialis muscle to the anterior interosseous nerve for treatment for lower brachial plexus lesions: case report. J Hand Surg Am 2011;36(03):394-397

8 Brown JM, Yee A, Mackinnon SE. Distal median to ulnar nerve transfers to restore ulnar motor and sensory function within the hand: technical nuances. Neurosurgery 2009;65(05):966-977, discussion 977-978

9 Nath RK, Mackinnon SE, Shenaq SM. New nerve transfers following peripheral nerve injuries. Oper Techn Plast Reconstr Surg. 1997;4(01):2-11

10 Johnston RB, Zachary L, Dellon AL, Mackinnon SE, Gottlieb L. The effect of a distal site of compression on neural regeneration. J Reconstr Microsurg 1993;9(04):271-274, discussion 274-275

11 Ruijs AC, Jaquet JB, Kalmijn S, Giele H, Hovius SE. Median and ulnar nerve injuries: a meta-analysis of predictors of motor and sensory recovery after modern microsurgical nerve repair. Plast Reconstr Surg 2005;116(02):484-494, discussion 495-496

12 Oberlin C, Béal D, Leechavengvongs S, Salon A, Dauge MC, Sarcy JJ. Nerve transfer to biceps muscle using a part of ulnar nerve for C5-C6 avulsion of the brachial plexus: anatomical study and report of four cases. J Hand Surg Am 1994;19(02):232-237

13 Tung TH, Novak CB, Mackinnon SE. Nerve transfers to the biceps and brachialis branches to improve elbow flexion strength after brachial plexus injuries. J Neurosurg 2003;98(02):313-318

14 Tuttle HK. Exposure of the brachial plexus with nerve transplantation. JAMA 1913;61:1515-1517

15 Robla-Costales J, Socolovsky M, Di Masi G, et al. Técnicas de reconstrucción nerviosa en cirugía del plexo braquial traumatizadoParte 1: Transferencias nerviosas extraplexuales. Neurocirugia (Astur) 2011;22(06):507-520

16 Hattori Y, Doy K, Toh S, Baliarsing AS. Approach to the Spinal Accesory Nerve. J Hand Surg [Br] 2001;26A:1073-1076

17 Bertelli JA, Ghizoni MF. Transfer of the accessory nerve to the suprascapular nerve in brachial plexus reconstruction. J Hand Surg Am 2007;32(07):989-998

18 Brunelli G, Monini L. Neurotization of avulsed roots of brachial plexus by means of anterior nerves of cervical plexus. Clin Plast Surg 1984;11(01):149-152

19 Chuang DC, Cheng SL, Wei FC, Wu CL, Ho YS. Clinical evaluation of C7 spinal nerve transection: 21 patients with at least 2 years' follow-up. Br J Plast Surg 1998;51(04):285-290 